\title{
Sedanter Kadın ve Erkekerde Beden Kitle İndeksi ile Pes Planus, Denge, Yaşam Kalitesi ve Ağrı Düzeyleri Arasındaki İlişki
}

\author{
Arzu KESKIN AKTAN 國, Özden KUTLAY ${ }^{1}$
}

Öz

Amaç: Bu çalışmanın amacı sedanter erkek ve kadınlarda beden kitle indeksi ile pes planus, denge, yaşam kalitesi ve ağrı arasındaki ilişkinin araștırılmasıdır.

Gereç ve Yöntemler: Çalışmamıza 18-30 yaş aralığında, toplam 82 sedanter gönüllü (39 erkek, 43 kadın) katıldı. Katılımcıların fiziksel aktivite düzeyleri Uluslararası Fiziksel Aktivite Ölçeği ile değerlendirildi ve beden kitle indeksleri hesaplandı. Her iki ayak için pes planus değerlendirmesi Naviküler Düşme Testi (NDT) ile yapıldı. Statik denge ölçümü Tek Ayak Üstünde Durma testi ile, dinamik denge ölçümü ise Dört Adım Kare ve Zamanlı Kalk-Yürü testleri ile yapıldı. Yaşam kalitesinin değerlendirilmesinde Kısa Form-36 (SF-36) ölçeği kullanıldı, ağrı değerlendirmesi ise Vizuel Analog Skala (VAS) ile yapıldı.

Bulgular: BKİ ile yaş, kilo, NDT, Dinamik Denge-Zamanlı Kalk ve Yürü test puanları arasında pozitif yönde; Statik Denge, SF-36-Fiziksel fonksiyon, SF-36-Genel sağlık puanları arasında ise negatif yönde ilişki saptandı. Erkeklerde boy, kilo ve BKİ' nin yanı sıra NDT-sağ ayak ölçümü daha yüksek bulundu. NDT sınıflamasına göre yapılan gruplamada pes planusu olan katılımcıların kilo, BKİ ve VAS (şiddetli) ölçümlerinin daha yüksek olduğu, ayrıca statik ve dinamik dengelerinin daha kötü olduğu görüldü.

Sonuç: Bulgularımız sedanter genç-erişkinlerde beden kitle indeksinin, pes planus, vücut dengesi ve yaşam kalitesi ile ilişkili olduğunu göstermekte, ayrıca pes planusun statik ve dinamik vücut dengesini olumsuz yönde etkilediğine işaret etmektedir.

Anahtar Kelimeler: Beden kitle indeksi; pes planus; denge; yaşam kalitesi; ağrı.

\section{The Relationship between Body Mass Index and Pes Planus, Balance, Quality of Life and Pain Levels in Sedentary Female and Male}

\begin{abstract}
Aim: This study aimed to investigate the relationship between body mass index and pes planus, balance, quality of life, and pain in sedentary female and male.

Material and Methods: A total of 82 sedentary volunteers (39 men, 43 women) between the ages of 18-30 participated in our study. Physical activity levels of the participants were evaluated with the International Physical Activity Questionnaire, and body mass index was calculated. Pes planus was performed with Navicular Drop Test (NDT) for both feet. Static balance measurement was performed with Stand on One Foot test, and dynamic balance measurement was performed with Four Step Square and Timed Up-Go tests. The Short Form-36 (SF-36) scale was used to assess the quality of life, and the pain assessment was made with Visual Analogue Scale (VAS).

Results: BMI was positively correlated with age, weight, NDT, Dynamic Balance-Timed Up and Go test, while negatively correlated with Static Balance, SF-36-Physical function, and SF-36-General health scores. NDT-right foot measurement was found to be higher in men as well as height, weight, and BMI. In the grouping made according to the NDT classification, it was seen that the participants with pes planus had higher weight, BMI, and VAS (severe) measurements, and their static and dynamic balance was worse.

Conclusion: Our findings show that body mass index is correlated with pes planus, body balance, and quality of life in
\end{abstract}

1 Afyonkarahisar Sağlık Bilimleri Üniversitesi, Tıp Fakültesi, Fizyoloji Anabilim Dalı, Afyonkarahisar/Türkiye

Sorumlu Yazar / Corresponding Author: Arzu KESKIN AKTAN e-mail: arzu.aktan@afsu.edu.tr, arzukeskinaktan@gmail.com Geliş Tarihi / Received: 24.10.2020, Kabul Tarihi / Accepted: 04.11.2021 
sedentary young-adults, and also indicate that pes planus negatively affects the static and dynamic body balance.

Keywords: Body mass index; pes planus; balance; quality of life; pain

\section{GÍRIS}

Sedanter yaşam tarzı mortalite için en önemli risk faktörlerinden birisi olarak kabul edilmektedir. Fiziksel açıdan inaktif bireylerde solunum ve dolaşım sistemini etkileyen kronik hastalıkların görülme sıklığı artmakta, ayrıca zaman içinde gelişen metabolik bozukluklar obezite ile birlikte anormal vücut kompozisyonlarının gelişimine neden olmaktadır. Vücut kompozisyonu, vücuttaki kas, kemik ve yağ oranlarını ifade eder ve genel popülasyonun sağlık durumunu değerlendirmek amacıyla yaygın şekilde kullanılır $(1,2)$. Beden kitle indeksi, vücut kompozisyonun değerlendirilmesinde kullanılan oldukça pratik yöntemlerden birisidir ve kilonun boyla ilişkisine bakarak $\left(\mathrm{kg} / \mathrm{m}^{2}\right)$ vücut kilosunun normal sinırlarda olup olmadığının tespit edilmesini sağlar (3). Özellikle çocukluk çağı ve erişkinlik dönemlerinde fazla kilo ve yüksek beden kitle indeksi, vücut biyomekaniğinde bozulmalara ayrıca, ayakta pes planus (düz tabanlık) gibi yapısal deformitelerin gelişimine yol açabilmektedir (4). Ayak, hem statik hem de dinamik özellikleri ile vücut ağırlığının taşınması, yürüme fonksiyonunun yerine getirilmesi ve temas edilen dış ortama adaptasyonun sağlanmasında görev alır. Bu fonksiyonları ile oldukça kompleks bir yapıya sahip olan ayak, aynı zamanda iç ve dış stresörlere en çok maruz kalan yapılardan birisidir (5). Ayak biyomekanisinin bozulmasına yol açan ve ayakta en sık karşılaşılan deformitelerden birisi pes planustur. Pes planus, arcus longitudinalis medialis (MLA, medial longitudinal ark) yüksekliğinin normalden daha az olması veya arkın tamamen çökmesi sonucu oluşmaktadır. Vücuttaki ağırlık artışına bağlı olarak arka binen yük artacağından medial longitudinal arkın yüksekliğinde azalma ile pes planusun gelişebileceği, hatta ark1 destekleyen bağlardaki laksiteyle ilişkili olarak pes planusa hipermobilitenin de eşlik edebileceği düşünülmektedir (4).

Vücut dengesi, destek alanı içerisinde vücudun kendi pozisyonunu koruma yeteneğidir. Vücut dengesi statik ve dinamik denge olarak ikiye ayrılır. Statik denge, vücudun belli bir pozisyonda kendini koruma ihtiyacını karşılarken, dinamik denge ise vücudun hareket halindeki dengesinin sürdürülmesini sağlar. Günlük yaşam aktiviteleri, iç ve diş uyaranlarla birlikte statik/dinamik dengenin ve postüral kontrolün kombine kullanımını gerektirir. İntramusküler yağ infiltrasyonu gibi vücut kompozisyonunda meydana gelen değişiklikler kas kalitesini ve performansinı azaltmakta, kuvvet ve fonksiyonel mobilitede bozulmalara neden olmaktadır. Özellikle, alt ekstremitelerdeki kuvvet kayıplarının, dengedeki azalma/bozulma ile ilişkili olduğu bilinmektedir $(6,7)$.

Yaşam kalitesi çok boyutlu bir kavramdır ve bireysel algı, yaşam doyumu, iyilik ve refah olarak tanımlamaktadır (8). Yaşam kalitesini değerlendirmek amacıyla geliştirilen ölçekler, bireyin fiziksel, ruhsal ve sosyal iyilik halini bir bütün olarak değerlendirmektedir. Artmış beden kitle indeksi, pek çok sağlık sorunu yanında, bireyin yaşam kalitesini ve ruhsal durumunu da olumsuz yönde etkileyebilmektedir. Vücut ağırlığındaki aşırı artışın ve eşlik eden ayak/bacak problemlerinin fonksiyonel kisitlilıklara neden olduğu ve bu durumun bireylerin yaşam kalitesinde bozulmalara neden olabileceği belirtilmektedir $(9,10)$. Pes planusta ark yüksekliğindeki azalma veya tamamen kayboluş postüral dizilim bozukluklarına, arkı destekleyen kas, tendon ve ligamentlerde zayıflık gibi biyomekaniksel bozukluklara, kas-iskelet sistemi problemlerine, nörolojik defisitlere ve dolayısıyla ağrı şikayetlerinde artışa sebep olmaktadır. Biz de bu bağlamda genç erişkin yaş grubunda yer alan 18-30 yaş aralığındaki sedanter kişilerde beden kitle indeksi, pes planus, denge, yaşam kalitesi ve ağrı düzeylerini araştırdık. Ayrıca bu çalışma ile bahsi geçen değişkenler arasındaki olası ilişkileri ve cinsiyete bağlı farklılaşmaları da gösterebilme imkanı bulduk.

\section{GEREÇ VE YÖNTEMLER Örneklem}

Çalışmaya 18-30 yaş aralığında, sedanter, sağ el kullanımı dominant olan sağlıklı kadın $(n=43)$ ve erkek $(n=39)$ katılımcılar dahil edildi. Ortopedik, nörolojik, kardiyovasküler, solunum vb sistemleri etkileyen kronik herhangi bir hastalığı olanlar ile travma ve/veya cerrahi öyküsü olanlar çalışmaya dahil edilmedi. Çalışma için gerekli katılımcı sayısını hesaplamak için G*Power 3.1.9.2 programı kullanıldı ve 82 katılımcıdan oluşan bir örneklemin etki büyüklüğü orta düzeyde $(0,30)$ olan bir etkiyi çift kuyruklu testte 0,05 düzeyinde tespit için 0,80 istatistiksel güç sağlayacağı hesapland.

\section{Veri Toplama Araçları}

Tüm katılımcıların yaş, cinsiyet, boy, kilo, genel sağlık durumları, hastalık öyküsü vb. bilgileri sosyo-demografik bilgi formu ile alındı. Çalışmaya sedanter bireyler kabul edileceği için fiziksel aktivite düzeyinin tespit edilebilmesi amaciyla Uluslararası Fiziksel Aktivite Ölçeği-Kısa Form (IPAQ; International Physical Activity Questionnaire- short form) kullanıldı. Bu ölçek aracılığı ile hesaplanan ve fiziksel aktivite düzeyi 3000 METdk/hafta'dan az olan katılımcilar sedanter kabul edilerek çalışmaya dahil edildi $(11,12)$ (IPAQ scoring protocolwww.ipaq.ki.se). Yapılan ön değerlendirmeler sonucunda çalışmaya dahil edilme kriterlerini taşıyanlarda aşağıda açıklaması verilen değerlendirilmeler yapıldı.

Beden Kitle İndeksi (BKI): Beden kitle indeksi kilonun boyla ilişkisine bakan dolaylı bir yöntemdir ve BKI' nin hesaplanmasında $\mathrm{BKI}=\left[\begin{array}{lll}\mathrm{kilo} & (\mathrm{kg}) / \mathrm{boy} & \left(\mathrm{m}^{2}\right)\end{array}\right]$ formülü kullanılmıştır (3).

Ağrı Değerlendirmesi: Katılımcıların ayak bölgesinde deneyimledikleri ağrı düzeyleri, 3 ayrı durum (istirahat, fiziksel aktivite ve şiddetli) için Vizuel Analog Skala (VAS) ile değerlendirilmiştir. VAS, güvenirliliği kanıtlanmış, ağrı şiddetini ölçen bir skaladır (13). Bu değerlendirme yönteminde katılımcılardan bir ucu "ağrı yok (0)", diğer ucu ise "dayanılmaz şiddette ağrı (10)" şeklinde işaretlenmiş $10 \mathrm{~cm}$ 'lik düz bir çizgi üzerinde hissettikleri ağrı düzeyini işaretlemeleri istenmiştir.

Naviküler Düşme Testi: Naviküler düşme testi, pes planusun varlığını ve derecesini belirlemek amacıyla klinikte kullanılan bir testtir. Bu testte öncelikle naviküler tüberkül palpe edilip işaretlenir ve kişi oturma pozisyonda ve ayakları sadece yerle temas halindeyken (ayaklarına ağırlık vermeden) naviküler tüberkül ile 
zemin arasındaki mesafe kumpasla ölçülür. Daha sonra kişi ayağa kalkar ve ayaklarına eşit ağırlık verdiği pozisyonda iken naviküler tüberkül ile zemin arasındaki mesafe tekrar ölçülür. Ölçümler bilateral yapılır ve milimetre $(\mathrm{mm})$ ya da santimetre $(\mathrm{cm})$ cinsinden kaydedilir. Naviküler düşme testinde ağırlıklı-ağırlıksız ölçüm arası fark 5-9 mm arası normal (nötral), $10 \mathrm{~mm}$ ve üzeri pronasyon, $4 \mathrm{~mm}$ ve altı supinasyon olarak kabul edilmektedir (14). Ayağın pronasyonu pes planusa, supinasyonu ise pes cavusa yönelimi göstermektedir.

Denge Değerlendirmesi: Statik dengenin değerlendirilmesi amacıyla tüm katılımcılara "Tek ayak üstünde durma testi” uygulanmıştır (15). Bu test için kişilerin topuksuz ayakkabı veya çıplak ayak ile sert ve düz bir zeminde tek ayak üstünde durmaları gerekmektedir. Test esnasında eller gövdeye kenetli olmalı ve hiçbir yerden destek alınmamalıdır. Bu şekilde tek ayak üzerinde durma süresinin 10 sn'den kısa olması denge bozukluğuna, 5 sn'den kısa olması ise düşme riskinin olduğuna işaret etmektedir. Test gözler açık ve kapalıyken ayrı ayrı yapılır. Statik dengenin normal kabul edilebilmesi için bireyin dengesini tüm aşamalarda minimum 30 sn koruması gerekmektedir.

Dinamik dengenin değerlendirilmesinde ise 2 ayrı test kullanılmıştır: "Dört adım kare testi" ve "Zamanlı kalk ve yürü testi”. Dört adım kare testinde zemine bir artı işareti çizilir ve oluşan dört kare numaralandırılır. 1 numaralı kareden başlanarak sırasıyla (2-3-4-1-4-3-2-1) nolu karelere olabildiğince hızlı bir şekilde adım atılır. Adımlama sürecinde çizgilere basılmaması ve her bir karede iki ayağın da zeminle temas etmiş olması gerekir. Bir kez deneme yaptırıldıktan sonra test aşamasına geçilir ve kronometre ile takip edilen testin tamamlanma süresi kaydedilir (16).

Zamanlı kalk ve yürü testinde ise testin uygulanacağ 1 kişiler bir sandalyeye oturtulur ve önünde 3 metrelik mesafe işaretlenir. Katılımcılardan bu mesafeyi normal hız ve paternde yürüyüp geri dönerek tamamlamaları istenir. $\mathrm{Bu}$ esnada kronometre ile ölçülen süre kaydedilerek değerlendirme tamamlanır (17).

Kisa Form-36 (SF-36; short form-36): SF-36 genellikle 14 yaş ve üstü bireylerde yaşam kalitesini değerlendirmek amacıyla kullanılan ve kişinin sağlık durumunu olumsuz ve olumlu yönleriyle ele alan bir ölçektir (18). SF-36'nın Türkçe versiyonunun güvenirlik ve geçerlilik çalışması Koçyiğit ve arkadaşları tarafından yapılmıştır (19). SF36'nın sekiz alt boyutu bulunmaktadır (fiziksel fonksiyon, fiziksel rol güçlendirme, emosyonel rol güçlendirme, enerji, mental sağlık, sosyal fonksiyon, vücut ağrısı, genel sağlı) ve her alt boyut için ayrı puan hesaplaması yapılmaktadır. Alt boyutların puanları 0-100 arasında değişmektedir. Ölçekten alınan puanların yüksek olması yaşam kalitesindeki artışa, düşük olması ise yaşam kalitesindeki azalmaya işaret etmektedir (20).

\section{Çalışmanın Etik Yönü}

Çalışmaya başlanmadan önce Erciyes Üniversitesi Klinik Araştırmalar Etik Kurulu'ndan (Tarih: 24.07.2019, Karar No:2019/561) Etik Kurul Onayı ve çalışmanın yürütüldüğü Nuh Naci Yazgan Üniversitesi, Sağlık Bilimleri Fakültesi'nden gerekli kurumsal izinler alındı. Tüm katılımcılara araştırmanın amacı ile ilgili bilgi verildikten sonra katılımcıların sözlü ve yazılı onamları alındı. Çalışma, Helsinki Deklerasyon Prensiplerine uygun olarak yapıldı, ayrıca Araştırma ve Yayın Etiğine uyuldu.

\section{İstatistiksel Analiz}

Çalışmadan elde edilen veriler "ortalama \pm standart sapma" şeklinde sunuldu. Verilerin analizi için SPSS 22.0 programı kullanıldı. Verilerin normal dağılıma uygunluğu Kolmogorov-Smirnov ve Shapiro-Wilk testleri ile değerlendirildi. Değişkenler arasındaki ilişkilerin belirlenmesi için Pearson korelasyon testi, kadın ve erkek cinsiyete ait bulguların kıyaslanması için bağımsız gruplar t-testi, Naviküler Düşme Testi sınıflamasına göre belirlenen 3 gruba ait değişkenlerin kıyaslanması için tek yönlü ANOVA (post-hoc LSD) testi yapıldı. $p<0,05$ düzeyi istatistiki olarak anlamlı kabul edildi.

\section{BULGULAR}

Çalışmaya dahil edilen toplam 82 katılımcının \% 52,4'ü kadınlardan $(n=43), \%$ 47,6'sı ise erkeklerden $(n=39)$ oluşmaktadır. Kadın ve erkek katılımcıların yaş ortalamaları arasında anlamlı bir fark bulunmazken $(p=0,964)$, erkeklerin boy $(\mathrm{p}<0,001)$, kilo $(\mathrm{p}<0,001)$ ve beden kitle indeksleri $(p=0,019)$ kadınlardan anlamlı düzeyde yüksektir. Ayrıca, erkeklerde sağ ayak için ölçülen naviküler düşme mesafesi (NDT-sağ ayak) kadınlardan anlamlı düzeyde daha fazladır $(p=0,015)$. Araştırılan diğer değişkenler; fiziksel aktivite düzeyi (IPAQ), ağrı skorları (VAS), sol ayak için ölçülen naviküler düşme mesafesi (NDT-sol ayak), statik/dinamik denge testi sonuçları ve yaşam kalitesini 8 alt boyutta değerlendiren SF-36 ölçek puanları arasında, cinsiyete göre anlamlı bir fark bulunmamıştır (tüm $\mathrm{p}$ değerleri p>0,05) (Tablo 1).

Cinsiyete göre yapılan kıyaslamaların yanı sıra tüm katılımcılar Naviküler Düşme Testi (NDT) sonuçlarına göre 3 gruba ayrılmış ve tüm katılımcılar sağ ekstremiteleri dominant olan kişilerden seçildiği için bu gruplamada sağ ayaktan yapılan ölçümler referans alınmıştır. NDT sınıflamasına göre oluşturulan gruplar; 1) Supinasyon (0-4 mm, $\mathrm{n}=12)$, 2) Normal (5-9 mm, $\mathrm{n}=38$ ), 3) Pronasyon $(\geq 10 \mathrm{~mm}, \mathrm{n}=32$ ) şeklindedir (Tablo 2). Naviküler düşme düzeyi "normal" kabul edilen gruba kiyasla "pronasyon" grubunun ortalama kilosu $(\mathrm{p}<0,001)$, BKİ'si ( $<<0,001)$, VAS-şiddetli ağrı düzeyi $(p=0,050)$, NDT-sağ ayak ölçümü $(\mathrm{p}<0,001)$, NDT-sol ayak ölçümü $(\mathrm{p}<0,001)$ daha yüksek, ayrıca Dinamik denge testlerinden Dört Adım Kare testini tamamlama süresi daha uzundur $(\mathrm{p}=0,031)$. Yine "pronasyon" grubunda gözler açık ve kapalı olarak yapılan Statik Denge Testi süreleri "normal" gruba kiyasla daha kisadır $(\mathrm{p}<0,001)$. "Supinasyon" grubunda ise "normal" gruba kiyasla VASfiziksel aktivite esnasındaki ağrı düzeyi daha yüksek ( $p=0,027)$, NDT-sağ ayak ölçümü daha düşük $(p<0,001)$ bulunmuştur. Pronasyon ve supinasyon grupları arasında ise anlamlı fark bulunan değişkenler kilo $(\mathrm{p}<0,001)$, BKI ( $\mathrm{p}<0,001)$, statik denge-gözler açık $(\mathrm{p}=0,031)$, NDT-sağ ayak ölçümü $(p<0,001)$ ve NDT-sol ayak ölçümüdür $(\mathrm{p}<0,001)$. Araştırılan diğer değişkenler (yaş, boy, IPAQ, VAS-istirahat, Dinamik Denge-zamanlı kalk ve yürü, SF36) açısından gruplar arasında anlamlı fark bulunmamıştır (tüm p değerleri >0,05) (Tablo 2). 
Tablo 1. Kadın ve erkek katılımcılara ait bulguların karşılaştırılması

\begin{tabular}{|c|c|c|c|c|}
\hline & $\begin{array}{l}\text { Toplam } \\
n=82 \\
\text { Ort } \pm \text { S.S. }\end{array}$ & $\begin{array}{l}\text { Kadın } \\
n=43 \\
\text { Ort } \pm \text { S.S. }\end{array}$ & $\begin{array}{l}\text { Erkek } \\
n=39 \\
\text { Ort } \pm \text { S.S. }\end{array}$ & $* p$ \\
\hline Yaş $(y l l)$ & $22,12 \pm 3,71$ & $22,14 \pm 3,62$ & $22,1 \pm 3,86$ & 0,964 \\
\hline Boy $(\mathrm{cm})$ & $169,37 \pm 8,81$ & $164,21 \pm 6,07$ & $175,05 \pm 7,84$ & $<0,001$ \\
\hline Kilo $(k g)$ & $70,06 \pm 15,31$ & $62,47 \pm 12,59$ & $78,43 \pm 13,69$ & $<0,001$ \\
\hline $\mathrm{BKI}\left(\mathrm{kg} / \mathrm{m}^{2}\right)$ & $24,33 \pm 4,95$ & $23,11 \pm 4,34$ & $25,67 \pm 5,29$ & 0,019 \\
\hline IPAQ (MET-dk/hafta) & $1239,79 \pm 524,88$ & $1211,93 \pm 511,14$ & $1270,5 \pm 544,64$ & 0,617 \\
\hline VAS-istirahat (cm) & $1,12 \pm 1,39$ & $1,05 \pm 1,51$ & $1,21 \pm 1,26$ & 0,609 \\
\hline VAS-fiziksel aktivite $(\mathrm{cm})$ & $3,2 \pm 2,97$ & $3,21 \pm 3,7$ & $3,18 \pm 1,92$ & 0,964 \\
\hline VAS-şiddetli $(\mathrm{cm})$ & $6,55 \pm 1,95$ & $6,58 \pm 2$ & $6,51 \pm 1,92$ & 0,875 \\
\hline NDT- Săg ayak $(\mathrm{cm})$ & $8,3 \pm 4,05$ & $7,27 \pm 3,72$ & $9,44 \pm 4,14$ & 0,015 \\
\hline NDT-Sol ayak (cm) & $8,05 \pm 3,95$ & $7,40 \pm 3,76$ & $8,77 \pm 4,08$ & 0,116 \\
\hline Statik Denge-Gözler Açık (sn) & $143,57 \pm 118,05$ & $138,26 \pm 123,06$ & $149,44 \pm 113,58$ & 0,671 \\
\hline Statik Denge-Gözler Kapalı (sn) & $30,09 \pm 26,01$ & $29,40 \pm 27,83$ & $30,86 \pm 24,18$ & 0,803 \\
\hline Dinamik Denge -Dört Adım Kare (sn) & $8,3 \pm 5,8$ & $8,77 \pm 7,63$ & $7,77 \pm 2,64$ & 0,440 \\
\hline 1. Fiziksel fonksiyon & $90,18 \pm 15,1$ & $90,47 \pm 15,5$ & $89,87 \pm 14,85$ & 0,860 \\
\hline 2. Fiziksel rol güçlendirme & $87,01 \pm 27,25$ & $90,70 \pm 22,51$ & $82,95 \pm 31,47$ & 0,200 \\
\hline 3. Emosyonel rol güçlendirme & $77,23 \pm 37,36$ & $78,30 \pm 36,28$ & $76,06 \pm 38,96$ & 0,789 \\
\hline 4. Enerji & $55,4 \pm 20,73$ & $51,35 \pm 19,06$ & $59,87 \pm 21,81$ & 0,063 \\
\hline 5. Mental sağlık & $63,37 \pm 18,40$ & $61,98 \pm 17,5$ & $64,9 \pm 19,47$ & 0,476 \\
\hline 6. Sosyal fonksiyon & $78,14 \pm 22,60$ & $82,56 \pm 17,28$ & $73,27 \pm 26,69$ & 0,063 \\
\hline 7. Vücut ăgrisı & $81,62 \pm 81,15$ & $73,72 \pm 23,21$ & $90,32 \pm 115,3$ & 0,358 \\
\hline 8. Genel sağlık & $60,50 \pm 14,58$ & $60,12 \pm 15,49$ & $60,92 \pm 13,7$ & 0,804 \\
\hline
\end{tabular}

Ort \pm S.S.: Ortalama \pm Standart Sapma, BKİ: Beden kitle indeksi, IPAQ: International Physical Activity Questionnaire-short form (Uluslararası Fiziksel Aktivite Ölçeği-kısa form), VAS: Vizuel Analog Skala, NDT: Naviküler Düşme Testi, SF-36: Short Form-36 (Kısa Form-36).

Tablo 2. Naviküler düşme testi sonuçlarına göre oluşturulan gruplar ve ilgili karşılaştırmalar

\begin{tabular}{|c|c|c|c|c|}
\hline Toplam $n=82$ & $\begin{array}{l}\text { Supinasyon } \\
(0-4 \mathrm{~mm}) \\
n=12 \\
\text { Ort } \pm \text { S.S. }\end{array}$ & $\begin{array}{l}\text { Normal } \\
(5-9 \mathrm{~mm}) \\
n=38 \\
\text { Ort } \pm \text { S.S. }\end{array}$ & $\begin{array}{l}\text { Pronasyon } \\
(\geq 10 \mathrm{~mm}) \\
n=32 \\
\text { Ort } \pm \text { S.S. }\end{array}$ & $* * p$ \\
\hline Yaş $(y l l)$ & $21,08 \pm 3,32$ & $21,47 \pm 3,21$ & $23,03 \pm 4$ & 0,072 \\
\hline Boy $(\mathrm{cm})$ & $170,67 \pm 9,46$ & $169,79 \pm 9,61$ & $168,38 \pm 7,69$ & 0,691 \\
\hline Kilo $(\mathrm{kg})$ & $64,25 \pm 8,55$ & $61,97 \pm 11,05$ & $81,84 \pm 14,29$ & $<0,001$ \\
\hline $\mathrm{BKI}\left(\mathrm{kg} / \mathrm{m}^{2}\right)$ & $22,14 \pm 2,85$ & $21,28 \pm 2,59$ & $28,77 \pm 4,43$ & $<0,001$ \\
\hline IPAQ (MET-dk/hafta) & $1257,83 \pm 442,28$ & $1257,53 \pm 576,46$ & $1211,95 \pm 502,50$ & 0.931 \\
\hline VAS-istirahat $(\mathrm{cm})$ & $0,92 \pm 1,31$ & $1,03 \pm 1,30$ & $1,31 \pm 1,53$ & 0,600 \\
\hline VAS-fiziksel aktivite $(\mathrm{cm})$ & $4,83 \pm 6,25$ & $2,66 \pm 1,83$ & $3,22 \pm 1,95$ & 0,048 \\
\hline VAS-şiddetli $(\mathrm{cm})$ & $7,17 \pm 1,85$ & $6,03 \pm 2,12$ & $6,94 \pm 1,64$ & 0,045 \\
\hline NDT-Sağ ayak $(\mathrm{cm})$ & $3,08 \pm 1,68$ & $6,47 \pm 1,47$ & $12,42 \pm 2,67$ & $<0,001$ \\
\hline NDT-Sol ayak $(\mathrm{cm})$ & $4,5 \pm 3,03$ & $6,34 \pm 2,53$ & $11,41 \pm 3,13$ & $<0,001$ \\
\hline Statik Denge-Gözler Açık (sn) & $160,67 \pm 99,79$ & $191,08 \pm 133,80$ & $80,75 \pm 67,51$ & $<0,001$ \\
\hline Statik Denge-Gözler Kapalı (sn) & $30,8 \pm 25,87$ & $41,56 \pm 30,27$ & $16,21 \pm 8,74$ & $<0,001$ \\
\hline Dinamik Denge -Dört Adım Kare (sn) & $7,18 \pm 2,17$ & $7,12 \pm 2,06$ & $10,12 \pm 8,70$ & 0,046 \\
\hline Dinamik Denge- Zamanlı Kalk ve Yürü (sn) & $6,74 \pm 1,31$ & $7,07 \pm 1,74$ & $7,59 \pm 2,59$ & 0,394 \\
\hline \multicolumn{5}{|l|}{ SF-36 } \\
\hline 1. Fiziksel fonksiyon & $97,92 \pm 7,22$ & $89,47 \pm 17,27$ & $87,34 \pm 13,91$ & 0,051 \\
\hline 2. Fiziksel rol güçlendirme & $97,92 \pm 7,22$ & $86,18 \pm 27,69$ & $83,91 \pm 30,82$ & 0,309 \\
\hline 3. Emosyonel rol güçlendirme & $80,58 \pm 29,97$ & $74,56 \pm 40,6$ & $79,16 \pm 36,67$ & 0,832 \\
\hline 4. Enerji & $59,33 \pm 14,33$ & $57,66 \pm 23,29$ & $51,25 \pm 19,3$ & 0,343 \\
\hline 5. Mental să̆lık & $63,33 \pm 22,68$ & $63,42 \pm 20,07$ & $63,31 \pm 14,89$ & 1,000 \\
\hline 6. Sosyal fonksiyon & $90,63 \pm 9,42$ & $78,16 \pm 20,6$ & $70,44 \pm 26,71$ & 0,079 \\
\hline 7. Vücut ăgrtsı & $85,83 \pm 17,1$ & $90,76 \pm 16,56$ & $69,14 \pm 24,87$ & 0,535 \\
\hline 8. Genel săğlık & $62,08 \pm 13,73$ & $62,39 \pm 14,54$ & $57,66 \pm 14,92$ & 0,372 \\
\hline
\end{tabular}

Ort \pm S.S.: Ortalama \pm Standart Sapma, BKI: Beden kitle indeksi, IPAQ: International Physical Activity Questionnaire-short form (Uluslararası Fiziksel Aktivite Ölçeği-kısa form), VAS: Vizuel Analog Skala, NDT: Naviküler Düşme Testi, SF-36: Short Form-36 (K1sa Form-36). 
Araştırılan tüm değişkenler ile beden kitle indeksi ve NDT-sağ ayak ölçümü arasındaki ilişkiler Pearson korelasyon testi ile incelendiğinde, beden kitle indeksi ile yaş $(r=0,440 \mathrm{p}<0,001)$, kilo $(\mathrm{r}=0,880 \mathrm{p}<0,001)$, NDT-săg ayak $(\mathrm{r}=0,715 \mathrm{p}<0,001)$, NDT-sol ayak $(\mathrm{r}=0,618$ $\mathrm{p}<0,001)$, Dinamik Denge- Zamanlı Kalk Yürü $(\mathrm{r}=0,293$ $\mathrm{p}=0,008)$ test puanları arasında pozitif yönde; Statik Denge-gözler açık ( $\mathrm{r}=-0,398 \mathrm{p}<0,001)$, Statik Dengegözler kapalı $(\mathrm{r}=-0,449 \quad \mathrm{p}<0,001), \quad$ SF-36-Fiziksel fonksiyon $(r=-0,278 \mathrm{p}=0,011)$, SF-36-Genel Sağlik $(\mathrm{r}=-$ $0,238 \mathrm{p}=0,032$ ) puanları arasında negatif yönde ilişki saptanmıştır. Beden kitle indeksiyle pozitif yönde ilişkisi görülen NDT-sağ ayak ölçümünün de yaş $(\mathrm{r}=0,243$ $\mathrm{p}=0,028)$, kilo $(\mathrm{r}=0,61 \mathrm{p}<0,001)$, NDT-sol ayak ölçümü $(\mathrm{r}=0,721 \mathrm{p}<0,001)$ ile yine pozitif yönde; Statik Dengegözler açık ( $\mathrm{r}=-0,367 \mathrm{p}=0,001)$, Statik Denge-gözler kapalı $(\mathrm{r}=-0,336 \mathrm{p}=0,002)$, SF-36-Fiziksel fonksiyon $(\mathrm{r}=-$ $0,315 \mathrm{p}=0,004), \quad \mathrm{SF}-36-$ Sosyal fonksiyon $(\mathrm{r}=-0,235$ $\mathrm{p}=0,034)$ ve SF-36-Genel Sağlik $(\mathrm{r}=-0,248 \mathrm{p}=0,025)$ puanları arasında ise negatif yönde ilişki bulunmuştur (Tablo 3).

Tablo 3. Beden kitle indeksi ve NDT-Sağ ayak ölçümünün diğer değişikenler ile ilişkisi

\begin{tabular}{|c|c|c|c|c|c|}
\hline & & \multicolumn{2}{|c|}{ BKİ } & \multicolumn{2}{|c|}{ NDT-Sağ ayak } \\
\hline & & $\mathrm{r}$ & $\mathrm{p}$ & $\mathrm{r}$ & $\mathrm{p}$ \\
\hline 1 & BKİ & - & - & 0,715 & $<0,001$ \\
\hline 2 & Yas & 0,440 & $<0,001$ & 0,243 & 0,028 \\
\hline 3 & Boy & $-0,073$ & 0,516 & $-0,113$ & 0,314 \\
\hline 4 & Kilo & 0,880 & $<0,001$ & 0,610 & $<0,001$ \\
\hline 5 & IPAQ & 0,075 & 0,504 & $-0,072$ & 0,520 \\
\hline 6 & VAS-istirahat & 0,153 & 0,170 & 0,049 & 0,660 \\
\hline 7 & $\begin{array}{l}\text { VAS-fiziksel } \\
\text { aktivite }\end{array}$ & 0,041 & 0,713 & $-0,036$ & 0,750 \\
\hline 8 & VAS-şiddetli & 0,154 & 0,167 & 0,019 & 0,867 \\
\hline 9 & NDT-Sağ ayak & 0,715 & $<0,001$ & - & - \\
\hline 10 & NDT-Sol ayak & 0,618 & $<0,001$ & 0,721 & $<0,001$ \\
\hline 11 & $\begin{array}{l}\text { Statik Denge- } \\
\text { Gözler açı }\end{array}$ & $-0,398$ & $<0,001$ & $-0,367$ & 0,001 \\
\hline 12 & $\begin{array}{l}\text { Statik Denge- } \\
\text { Gözler kapall }\end{array}$ & $-0,449$ & $<0,001$ & $-0,336$ & 0,002 \\
\hline 13 & $\begin{array}{l}\text { Dinamik } \\
\text { Denge-Dört } \\
\text { Adlm Kare }\end{array}$ & 0,110 & 0,325 & 0,156 & 0,162 \\
\hline 14 & $\begin{array}{l}\text { Dinamik } \\
\text { Denge-Zamanll } \\
\text { Kalk ve Yürü }\end{array}$ & 0,293 & 0,008 & 0,174 & 0,118 \\
\hline 15 & SF-36 toplam & $-0,237$ & 0,032 & $-0,234$ & 0,035 \\
\hline 16 & $\begin{array}{l}\text { SF-36 fiziksel } \\
\text { fonksiyon }\end{array}$ & $-0,278$ & 0,011 & $-0,315$ & 0,004 \\
\hline 17 & $\begin{array}{l}\text { SF-36 fiziksel } \\
\text { rol } \\
\text { güçlendirme }\end{array}$ & $-0,167$ & 0,135 & $-0,158$ & 0,156 \\
\hline 18 & \begin{tabular}{|l}
$\begin{array}{l}\text { SF-36 } \\
\text { emosyonel rol } \\
\text { güclendirme }\end{array}$ \\
\end{tabular} & $-0,069$ & 0,537 & $-0,066$ & 0,555 \\
\hline 19 & SF-36 enerji & $-0,196$ & 0,078 & $-0,106$ & 0,344 \\
\hline 20 & $\begin{array}{l}\text { SF-36 mental } \\
\text { sağllk }\end{array}$ & $-0,058$ & 0,602 & $-0,029$ & 0,796 \\
\hline 21 & $\begin{array}{l}\text { SF-36 sosyal } \\
\text { fonksiyon }\end{array}$ & $-0,211$ & 0,057 & $-0,235$ & 0,034 \\
\hline 22 & $\begin{array}{l}\text { SF-36 vǘcut } \\
\text { ağrlst }\end{array}$ & $-0,097$ & 0,384 & $-0,151$ & 0,175 \\
\hline 23 & $\begin{array}{l}\text { SF-36 genel } \\
\text { sağllk }\end{array}$ & $-0,238$ & 0,032 & $-0,248$ & 0,025 \\
\hline
\end{tabular}

BKİ: Beden kitle indeksi,

IPAQ: International Physical Activity Questionnaire-short form (Uluslararası Fiziksel Aktivite Ölçeği-kısa form),

VAS: Vizuel Analog Skala,
NDT: Naviküler Düşme Testi, SF-36: Short Form-36 (K1sa Form-36).

\section{TARTIŞMA}

Çalışma bulgularımız beden kitle indeksi ile pes planus düzeyini değerlendirmek amacıyla kullandığımız Naviküler Düşme Testine ait ölçümler arasında pozitif yönde bir ilişki olduğunu göstermiştir. Beden kitle indeksi, pes planusun yanı sıra yaş, dinamik ve statik vücut dengesi, SF-36-fiziksel fonksiyon ve SF-36-genel sağlık düzeyiyle de ilişkili bulunmuştur. Ayakta medial arkın konfigürasyonu temelde yaş ve genetik faktörlerle belirlenir ve arkın gelişimi de büyüme ve gelişmenin doğal bir sonucudur. Pes planusun birden fazla etiyolojisi vardır ancak özellikle erken gelişim evresinde ve gençerişkinlik dönemlerinde pes planusa neden olan en önemli faktörler arasında artan kilo ve beden kitle indeksi sayılmaktadır (4,21-23). Pes planus, ayakta çekiç parmak ve bunyon gibi farklı deformitelere de yol açabilmekte, topukta, dizde, kalçada ve sırtta ağriya neden olabilmektedir (24).

Cinsiyete göre yapmış olduğumuz kıyaslamalarda, erkeklerde boy, kilo, beden kitle indeksinin yanı sıra NDT-sağ ayak ölçümleri daha yüksek bulunmuştur (Tablo 1). Pourghasem ve arkadaşları da 6-18 yaş aralığındaki çocuklarda yapmış oldukları çalışmada kızlara kıyasla oğlanlarda, ayrıca normal kilolu çocuklara kıyasla aşırı-kilolu ve obezlerde düz tabanlık görülme sıklığının daha yüksek olduğunu göstermiştir (22). Mevcut çalışmamızda NDT' nin sol ayak için yapılan ölçümlerinde ise cinsiyet açısından anlamlı bir fark bulunmamıştır. Bu durum muhtemelen tüm katılımcıların sağ dominant oluşu ve ağırlık aktarımının da sağ ayak üzerine daha fazla oluşuyla ilişkilidir. Erkek katılımıcılarda NDT-sağ ayak ölçümlerinin daha yüksek oluşu erkeklerde ark düşüklüğünün daha fazla olduğuna işaret etmektedir ancak ağrı, denge ve yaşam kalitesi puanları arasında cinsiyet açısından anlamlı bir fark saptanmamıştır. Esasen, ağrı, denge ve yaşam kalitesi, pes planusla ilişkili olabilecek değişkenlerdir (25), ancak Tablo 1' de görülebileceği üzere erkek katılımcılara ait ortalama NDT-sağ ayak ölçümü $(9,44 \pm 4,14)$ kadınlardan $(7,27 \pm 3,72)$ anlamlı düzeyde yüksek olsa da NDT sınıflamasında "normal (5-9 mm)" üst sınırına karşılık gelmektedir. $\mathrm{Bu}$ nedenle tüm katılımcılar NDT sinıflamasına göre (supinasyon, normal, pronasyon) 3 gruba ayrılmış ve bu gruplar arasında karşılaştırmalar yinelenmiştir. Ayakta pes planusa yönelimi gösteren naviküler düşmenin daha fazla olduğu $(\geq 10 \mathrm{~mm})$ pronasyon grubunda, normal gruba kıyasla kilo, beden kitle indeksi, NDT-sağ ve sol ayak ölçümlerinin, ayrıca şiddetli ağrı durumlarında tanımlanan VAS puanlarının daha yüksek olduğu görülmüştür (Tablo 2). Yine normal gruba kıyasla, pronasyon grubunda gözler açık ve kapalı iken değerlendirilen statik dengenin ve dört adım kare testiyle değerlendirilen dinamik dengenin daha kötü olduğu tespit edilmiştir. Bu bulgularımız pes planusun ağrı ve vücut dengesi üzerindeki olumsuz etkisine işaret etmektedir.

Aşırı supinasyonlu veya pronasyonlu ayak duruşları, eklem hareketliliğinde, yüzey temas alanında ve ayrıca stabil bir destek yüzeyi sağlayabilmek için kas aktivitelerinde yarattığı değişiklikler nedeniyle somatoduyusal girdide farklılaşmaya neden olur. Dolayısıyla, ayağın nötral pozisyonu dişında pronasyonda ya da 
supinasyonda oluşu ayak stabilizasyonunu ve vücut dengesini farklı şekillerde etkilemektedir. Yüksek ark ve hipomobil orta ayak ile karakterize aşırı supinasyonlu ayak (pes cavus), zemine yeterince uyum sağlayamadığından postüral stabilite ve dengeyi korumak için çevredeki kas-iskelet yapılarına olan yüklenmeyi artırır. Cote ve arkadaşları, denge merkezi etrafında salınımdaki ortalama sapmaları ifade eden stabilite indeksinin supisyona kıyasla pronasyonda daha yüksek olduğunu, ancak her iki grubun da nötr ayak tiplerine sahip olanlardan farklılaşmadığını göstermiştir (14). Mevcut çalışmamızın supinasyon grubunda, beklendiği üzere NDT-sağ ayak ölçümü normal gruptan anlamlı olarak düşüktür, ancak statik ve dinamik denge açısından normal gruptan farklılaşmadığı görülmüştür. Supinasyon grubunda fiziksel aktivite esnasında hissedilen ağrının (VAS-aktivite) normal gruba kıyasla daha yüksek olduğu görülmektedir. Nitekim, hem pes planus hem de pes cavusta ayak ağrısı oldukça yaygındır ve ayak deformiteleri, bel/bacak ağrısı, denge ve yaşam kalitesi ile ilişkilidir (26-29). Fonksiyonel kısıtlılıklara neden olan ayak deformiteleri kronikleştiğinde bireyin yaşam kalitesini olumsuz yönde etkilemektedir $(9,30)$. Çalışma bulgularımız NDT-sağ ayak ölçümünün hem statik denge ile hem de yaşam kalitesi ölçeğinin alt boyularından fiziksel fonksiyon, sosyal fonksiyon ve genel sağlık ile ilişkili olduğunu göstermektedir. Ancak yaşam kalitesi alt boyutları normal gruba kıyasla pronasyon ya da supinasyon gruplarında farklılaşmamıştır.

\section{SONUÇ}

Sonuç olarak, sedanter genç-erişkinlerde beden kitle indeksinin, pes planus, vücut dengesi ve yaşam kalitesi ile ilişkili olduğunu söyleyebiliriz. Yaş ve cinsiyete uygun vücut kompozisyona sahip olmak bireylerde oluşabilecek sekonder sağlık problemlerinin önüne geçilmesine imkan verecektir. Bu nedenle, bireylere fiziksel açıdan aktif ve doğru beslenme davranışlarını içeren bir yaşam tarzının kazandırılması toplum sağlığını korumada büyük önem arz etmektedir.

Yazarların Katkıları: Fikir/Kavram: A.K.A; Tasarım: A.K.A., Ö.K; Veri Toplama: A.K.A.; Analiz ve Yorum: A.K.A., Ö.K; Literatür Taraması: A.K.A., Ö.K.; Makale Yazımı: A.K.A.; Eleştirel İnceleme: A.K.A., Ö.K.

\section{KAYNAKLAR}

1. Zaccagni L, Barbieri D, Gualdi-Russo E. Body composition and physical activity in Italian university students. J Transl Med. 2014; 12(1): 1-9.

2. Yıldız A, Tarakcı D, Karantay Mutluay F. Genç erişkinlerde fiziksel aktivite düzeyi ile vücut kompozisyonu ilişkisi: Pilot çalışma. Sağlık Bilim ve Meslekleri Derg. 2015; 2(3): 297-305.

3. Lean MEJ, Han TS, Seidell JC. Impairment of health and quality of life using new US federal guidelines for the identification of obesity. Arch Intern Med. 1999; 159(8): 837-43.

4. Kim HW, Weinstein SL. Flatfoot in children: Differential diagnosis and management. Curr Orthop. 2000; 14(6): 441-7.
5. Rodgers MM. Dynamic biomechanics of the normal foot and ankle during walking and running. Phys Ther. 1988; 68(12): 1822-32.

6. Wolf L, Judge J, Whipple R, King M. Strength is a major factor in balance, gait, and the occurrence of falls downloaded from. Journals Gerontol Ser A. 1995; 50: 64-7.

7. Greve JMDA, Cuğ M, Dülgeroğlu D, Brech GC, Alonso AC. Relationship between anthropometric factors, gender, and balance under unstable conditions in young adults. Biomed Res Int. 2013; 2013: 1-5.

8. Bowling A. What things are important in people's lives? A survey of the public's judgements to inform scales of health related quality of life. Soc Sci Med. 1995; 41(10): 1447-62.

9. Lazarides SP, Hildreth A, Prassanna V, Talkhani I. Association amongst angular deformities in Hallux Valgus and impact of the deformity in health-related quality of life. Foot Ankle Surg. 2005; 11(4): 193-6.

10. Leveille S, Guralnik J, Ferrucci L, Hirsch R, Simonsick E, Hochberg M. Foot pain and disability in older persons: An epidemiologic survey. J Am Geriatr Soc. 1995 ; 43(5): 479-84.

11. Craig CL, Marshall AL, Sjöström M, Bauman AE, Booth ML, Ainsworth BE, et al. International physical activity questionnaire: 12-Country reliability and validity. Med Sci Sports Exerc. 2003; 35(8): 1381-95.

12. Zhao Y, Sigmund E, Sigmundova D, Lu Y. Comparison of physical activity between Olomouc and Beijing university students using an international physical activity questionnaire. Acta Univ Palacki Olomuc, Gymn. 2007; 37(4): 107-14.

13. Tiplady B, Jackson SHD, Maskrey VM, Swift CG. Validity and sensitivity of visual analogue scales in young and older healthy subjects. Age Ageing. 1998; 27(1): 63-6.

14. Cote KP, Brunet ME, Gansneder BM, Shultz SJ. Effects of pronated and supinated foot postures on static and dynamic postural stability. J Athl Train. 2005; 40(1): 41-6.

15. Vellas B, Wayne S, Romero L, Baumgartner R, Rubenstein L, Garry P. One-leg balance is an important predictor of injurious falls in older persons. J Am Geriatr Soc. 1997; 45(6): 735-8.

16. Dite W, Temple VA. A clinical test of stepping and change of direction to identify multiple falling older adults. Arch Phys Med Rehabil. 2002; 83(11): 156671.

17. Podsiadlo D, Richardson S. The timed up and go: A test of basic functional mobility for frail elderly persons. J Am Geriatr Soc. 1991; 39(2): 142-8.

18. Başaran S, Güzel R, Sarpel T. Yasam kalitesi ve sağlı sonuçlarını değerlendirme ölçütleri. Romatizma. 2005; 20(1): 55-63.

19. Koçyiğit H, Aydemir Ö, Fişek G, Ölmez N, Memiş A. Kısa form-36'nın türkçe versiyonunun güvenilirliği ve geçerliliği. İlaç ve Tedavi Derg. 1999; 12: 102-6.

20. Jensen IB, Bergström G, Ljungquist T, Bodin L. A 3year follow-up of a multidisciplinary rehabilitation programme for back and neck pain. Pain. 2005; 115(3): 273-83. 
21. Lee MS, Vanore J V., Thomas JL, Catanzariti AR, Kogler G, Kravitz SR, et al. Diagnosis and treatment of adult flatfoot. J Foot Ankle Surg. 2005; 44(2): 78113.

22. Pourghasem M, Kamali N, Farsi M, Soltanpour N. Prevalence of flatfoot among school students and its relationship with BMI. Acta Orthop Traumatol Turc. 2016; 50(5): 554-7.

23. Khan FR, Chevidikunnan MF, Mazi AF, Aljawi SF, Mizan FH, BinMulayh EA, et al. Factors affecting foot posture in young adults: A cross sectional study. J Musculoskelet Neuronal Interact. 2020; 20(2): 21622.

24. Walczak M, Napiontek M. Flexible flatfoot in children, a controversial subject. Ortop Pol. 2003; 68(4): 261-7.

25. Stolzman S, Irby MB, Callahan AB, Skelton JA. Pes planus and paediatric obesity: a systematic review of the literature. Clin Obes. 2015; 5(2): 52-9.

26. Mølgaard C, Lundbye-Christensen S, Simonsen O. High prevalence of foot problems in the Danish population: A survey of causes and associations. Foot. 2010; 20(1): 7-11.

27. Stubbs B, Schofield P, Patchay S. Mobility limitations and fall-related factors contribute to the reduced health-related quality of life in older adults with chronic musculoskeletal pain. Pain Pract. 2016; 16(1): 80-9.

28. Araújo F, Lucas R, Alegrete N, Azevedo A, Barros H. Sagittal standing posture, back pain, and quality of life among adults from the general population: A sexspecific association. Spine. 2014; 39(13): 782-94.

29. Wang Y Te, Chen JC, Lin YS. Effects of artificial texture insoles and foot arches on improving arch collapse in flat feet. Sensors. 2020; 20(13): 1-14.

30. Sivas F, Moran M, Yurdakul F, Koçak RU, Başkan B, Bodur H. Physical activity, musculoskeletal disorders, sleep, depression, and quality of life before and after bariatric surgery. Turkish J Phys Med Rehabil. 2020; 66(3): 281-90. 